\title{
Mammalian Transcription-Coupled Excision Repair
}

\author{
Wim Vermeulen ${ }^{1}$ and Maria Fousteri ${ }^{2}$ \\ ${ }^{1}$ Department of Genetics and Netherlands Proteomics Centre, Centre for Biomedical Genetics, \\ Erasmus Medical Centre, 3015 GE Rotterdam, The Netherlands \\ ${ }^{2}$ Institute of Molecular Biology and Genetics, Biomedical Sciences Research Centre Alexander \\ Fleming, 16672 Athens, Greece \\ Correspondence: fousteri@fleming.gr
}

\begin{abstract}
Transcriptional arrest caused by DNA damage is detrimental for cells and organisms as it impinges on gene expression and thereby on cell growth and survival. To alleviate transcriptional arrest, cells trigger a transcription-dependent genome surveillance pathway, termed transcription-coupled nucleotide excision repair (TC-NER) that ensures rapid removal of such transcription-impeding DNA lesions and prevents persistent stalling of transcription. Defective TC-NER is causatively linked to Cockayne syndrome, a rare severe genetic disorder with multisystem abnormalities that results in patients' death in early adulthood. Here we review recent data on how damage-arrested transcription is actively coupled to TC-NER in mammals and discuss new emerging models concerning the role of TC-NER-specific factors in this process.
\end{abstract}

$\mathrm{D}$ amaged DNA causes genome instability and reduces the fidelity of the replication process, resulting in increased mutagenesis, which are both at the basis of oncogenic transformation. In addition, lesions may block transcription, which causes disturbed cellular homeostasis and may trigger cellular senescence or apoptosis, resulting in damage-induced aging.

Despite the different DNA repair processes that remove many types of DNA lesions, replication and transcription machineries frequently encounter unrepaired lesions that disturb replication fork progression and transcription elongation or may even cause stalling. The structural complexity caused by lesion-stalled replication forks and transcription elongation complexes demands alternative strategies to deal with these genomic road blocks. Additional key repair processes exist to prevent replication fork collapse and promote fork restart (e.g., translesion synthesis and homologous recombination) or to resolve stalled transcription (transcription-coupled nucleotide excision repair; TC-NER).

\section{NUCLEOTIDE EXCISION REPAIR AND ITS COUPLING TO TRANSCRIPTION}

Within placental mammals, nucleotide excision repair (NER) is the sole DNA repair process that is able to remove the major UV-induced DNA lesions: cyclobutane-pyrimidine dimers (CPD) and 6-4 pyrimidinepyrimidone photo products

Editors: Errol C. Friedberg, Stephen J. Elledge, Alan R. Lehmann, Tomas Lindahl, and Marco Muzi-Falconi

Additional Perspectives on DNA Repair, Mutagenesis, and Other Responses to DNA Damage available at www.cshperspectives.org

Copyright (C) 2013 Cold Spring Harbor Laboratory Press; all rights reserved; doi: 10.1101/cshperspect.a012625

Cite this article as Cold Spring Harb Perspect Biol 2013;5:a012625 
(64PP). The significance of functional NER is illustrated by the severe clinical consequences associated with the autosomal recessive and UV-hypersensitive syndrome xeroderma pigmentosum (XP). XP patients carry inherited defects in one of the many NER genes causing extreme sun-sensitive skin and a more than 1000 -fold increased risk of skin cancer development as compared with the normal population. NER thus plays an important role in the removal of mutagenic DNA lesions from the genome and is a crucial process in protecting organisms against DNA damage-induced carcinogenesis. Increased mutagenesis as in XP cells is linked to defects in the global genome subpathway of NER (GG-NER, described below) and is induced by the persistence of unrepaired DNA lesions, which impinge on the fidelity of the replication process.

As mentioned above, DNA injuries also have a profound effect on transcription elongation. Stalled transcription forms an acute problem for cellular homeostasis by depriving cells of vital messages. In addition, DNA lesions in the transcribed strand may induce mutant transcripts as a consequence of transcriptional bypass over DNA lesions (Doetsch 2002; Marietta and Brooks 2007). A sophisticated subpathway of NER has been evolved to specifically resolve transcription complexes stalled at DNA lesions, thus allowing restoration of transcription and successful production of essential transcripts. Transcription-coupled NER (TC-NER) was originally dubbed as "preferential repair," as it was found that UV-induced photoproducts are removed more rapidly from transcribed sequences as compared with nontranscribed DNA (Bohr et al. 1985). Soon after this seminal discovery, the same research group of P.C. Hanawalt showed that only the transcribed strand of active genes is repaired faster by NER than the bulk of the genome (Mellon et al. 1987). TC-NER appears important to protect cells against UVlight-induced apoptosis (Ljungman and Zhang 1996). Cells from patients with the multisystem progeroid disorder, Cockayne syndrome (CS, see below for further details), which have an inherited defect in TC-NER, trigger the apoptotic response to UV via stabilization of $\mathrm{p} 53$, at much lower UV doses than TC-NER-proficient cells. It is likely that increased cell death in CS cells in response to UV light is not solely derived from disturbed cellular homeostasis because of a lack of vital transcripts, but that blocked transcription complexes are very cytotoxic structures, which induce a strong damage or persistent signaling cascade. Next to its vital role in protecting cells against a DDR that is too strong (apoptosis or permanent cell-cycle arrest), TC-NER seems also important in preventing UV-induced transcription-associated mutagenesis (Hendriks et al. 2010; Schärer 2013).

\section{THE SUBPATHWAYS OF NER}

In eukaryotic cells, initiation of TC-NER likely occurs by the physical blockage of RNA polymerase II (RNAPII) on lesions. Lesion-stalled RNAPII subsequently triggers the recruitment of the NER machinery (Svejstrup 2002). However, the bulk of the UV-induced DNA lesionsnot located in the transcribed strand of active genes-are repaired by the GG-NER subpathway of NER. In contrast to TC-NER, damage recognition in GG-NER occurs independent of transcription and requires the concerted action of the XPC/RAD23B and UV-DDB complexes (Gillet and Schärer 2006; Scrima et al. 2008; Yang 2008). The further processing of lesions in both TC-NER and GG-NER occurs via a common pathway (Schärer 2011), in which transcription factor TFIIH comes first after the damage is recognized. The intrinsic helicase activity of TFIIH together with the XPA protein is required to verify the lesion (Sugasawa et al. 2009). A lesion-bound complex involving at least the TFIIH, XPA, and RPA proteins provide the structural basis to load and properly orient the structure-specific endonucleases ERCC1/ $\mathrm{XPF}$ and XPG, which incise, respectively, the damaged strand $5^{\prime}$ and $3^{\prime}$ to the lesion. The consequent $25-30$ nucleotide gap is filled in by the replication machinery and sealed by DNA ligases (Moser et al. 2007; Ogi et al. 2010; Schärer 2013). At the cellular level, TC-NER or GG-NER deficiency results in UV hypersensitivity. As $>90 \%$ of the UV-induced DNA lesions are processed via GG-NER, excision of lesions and the 
subsequent gap-filling DNA synthesis, measured outside $S$ phase as unscheduled DNA synthesis or UDS, is only marginally affected in TC-NER-deficient cells as opposed to GGNER-deficient cells (Limsirichaikul et al. 2009; Nakazawa et al. 2010). Direct monitoring of TC-NER is significantly more laborious; only strand-specific damage removal assays are able to directly measure this NER subpathway (Mellon et al. 1987; Mellon 2005). However, a relatively easy transcription recovery assay is able to indirectly measure TC-NER (i.e., the so-called "recovery of RNA synthesis after UV irradiation or RRS"). RNAPII stalled at lesions causes an overall transcriptional decline, which in normal but not TC-NER-deficient cells recovers-in a dose- and time-dependent manner. RRS after UV can easily be assayed by pulse labeling cells (at different time points post-UV) with marked (radioactive or fluorescent) nucleotides (Mayne and Lehmann 1982; Nakazawa et al. 2010).

\section{HUMAN HEREDITARY TC-NER-DEFICIENT SYNDROMES}

Before discussing the molecular details of TCNER, we first summarize the consequences of inherited defects in this DDR pathway, to illustrate its biological significance. Genetic defects in TC-NER give rise to a heterogeneous and complex set of clinical features expressed by the different TC-NER-deficiency disorders:
Transcription-Dependent Genome Surveillance

Cockayne syndrome (CS), cerebro-oculo-facioskeletal syndrome (COFS), and UV-sensitive syndrome (UVSS).

\section{Cockayne Syndrome (CS)}

CS individuals are hypersensitive to UV irradiation, but do not display severe cutaneous features as seen in XP patients. XP represents the prototype NER-deficient disorder, and affected patients display severe sunburn, alternating hyper- and hypopigmentation and parchmentlike skin on exposed patches, and a more than 1000-fold increased incidence of skin cancer development. CS was first described in 1936 by E.A. Cockayne (Cockayne 1936), who discussed two siblings with cachectic dwarfism, retinopathy, and deafness.

In a follow-up study, the striking progressive nature of the disease was noticed (Cockayne 1946). Neill and Dingwall reported two other siblings that resemble, to a great extent, the cases published by Cockayne and were the first to connect it to progeria or premature aging (Neill and Dingwall 1950) (Fig. 1). In a comprehensive evaluation, Nance and Berry reviewed and categorized 140 different CS cases (Nance and Berry 1992). Typical symptoms include growth and development failure (cachectic dwarfism, microcephaly, peculiar face, deep sunken eyes, relative large extremities, impaired sexual development); progressive neurodegeneration (dys-
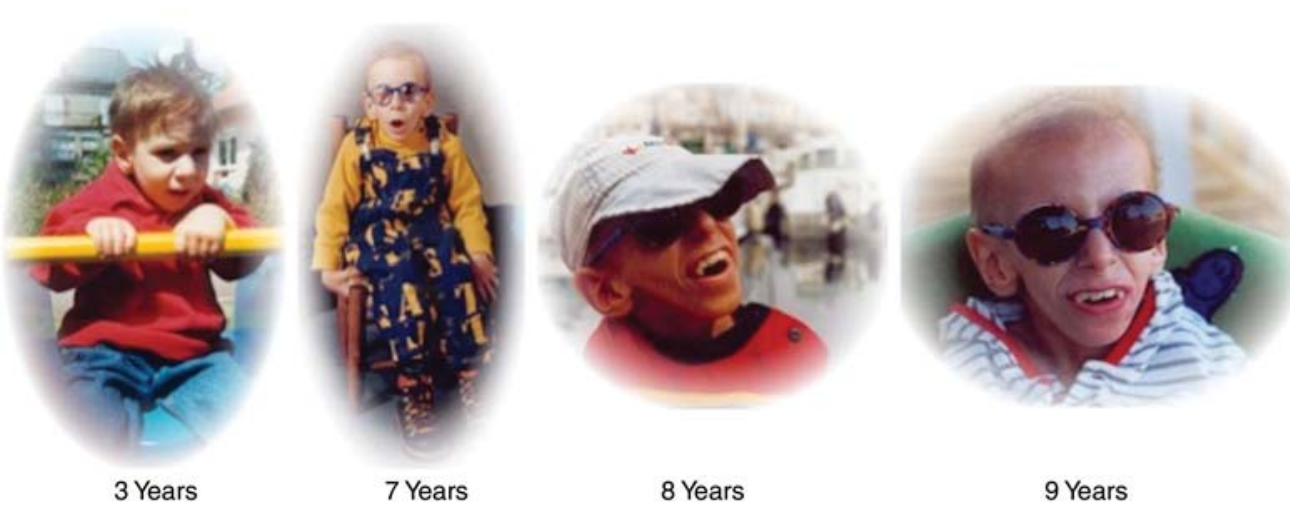

Figure 1. The devastating progression of Cockayne syndrome. Pictures of the family photo album of the CS patient Baptiste, who died at the age of 10 years old. 
myelination, calcification of the ganglia, ataxia), retinopathy and hearing loss; mental retardation; cataracts; progeroid appearance; and abnormal sensitivity to sunlight. The severe pathology leads to a low mean age of survival of approximately 12 years. Severity and progression of the symptoms varies among CS individuals and, based on these differences, the patients have been grouped into three subtypes: Type-I, patients with the classical form of CS are usually born without clear clinical symptoms and develop their first symptoms a few years after birth. Type-II, severe cases with early onset, neonatal or sometimes even intrauterine growth retardation and death before the first decade. Type-III, relatively mild, late onset patients with a lifespan of more than 30 years. CS is a rare disorder with an incidence estimated at 2.7 per million newborns in Western Europe (Kleijer et al. 2006). Genetic studies revealed that two genes are implicated in classical CS (Tanaka et al. 1981; Lehmann 1982): CSA, located on chromosome 5q12.1 encodes a 396 amino acid (44 kDa) WD-40 protein (Henning et al. 1995) and CSB, located on 10q11.23 encodes a 1493 amino-acid (168 kDa) ATPase protein, belonging to the SWI2/SNF2 family of chromatin remodelers (Troelstra et al. 1992a,b). The biochemical and molecular properties are detailed below. Mutational analysis among CS patients showed that for both genes $(\sim 60 \%$ CSB and $\sim 40 \%$ CSA) mutations are scattered over the genes with, to date, no clear genotypephenotype correlation (Laugel et al. 2010).

\section{Cerebro-Oculo-Facio-Skeletal Syndrome (COFS)}

COFS was first described in 1974 (Pena and Shokeir 1974; Preus and Fraser 1974), with most of the features (microcephaly, hypotonia, failure to thrive, eye defects, prominent nose, large ears, micrognathia, kyphoscoliosis, and osteoporosis) rather similar to those observed among CS patients. Meira et al. (2000) showed that three patients originally diagnosed as COFS show a CS-like cellular phenotype (UV hypersensitivity and defective recovery of RNA synthesis after UV). Mutational analysis revealed a homozygous nonsense mutation in the CSB gene, which creates a premature stop at position 1240 in the CSB protein. CS and COFS can thus be considered as two syndromes with a common pathogenesis, and it has been suggested in several studies that both actually represent the two borders of a clinical spectrum caused by the same biochemical defect (Laugel et al. 2008). As well as COFS patients with a CSB mutation, patients originally diagnosed as COFS but with mutations in the core NER genes XPD (Graham et al. 2001), XPG (Hamel et al. 1996; Nouspikel et al. 1997), and ERCC1 (Jaspers et al. 2007) have been identified. These latter patients with mutations in the core NER genes represent the most severe cases, likely because both TC-NER and GG-NER are affected.

\section{UV-Sensitive Syndrome $\left(\mathrm{UV}^{\mathrm{S}} \mathrm{S}\right)$}

A specific subgroup of rare photohypersensitive patients has been described, who display mainly cutaneous photohypersensitivity with mild dyspigmentation and freckling, but without increased skin cancer susceptibility as in XP and without CS-like neurologic and aging features (Itoh et al. 1995; summarized by Spivak 2005). The first UV-sensitive syndrome cases were described by Itoh et al. (1994). Surprisingly, the mild clinical manifestations were associated with a cellular DNA repair defect similar to that seen in CS patients (i.e., proficient GG-NER and defective TC-NER), expressed as the inability to recover RNA synthesis (RRS) after UV and defective transcription-coupled excision repair of the major UV lesion (CPD) (Spivak et al. 2002). This difference in phenotypic expression despite a similar TC-NER defect is particularly striking because two patients carry mutations in either the CSB (Horibata et al. 2004) or CSA genes (Nardo et al. 2009). The few other patients belong to a separate complementation group designated $\mathrm{UV}^{\mathrm{S}} \mathrm{S}$ $\mathrm{A}$, of which the implicated gene was unknown until recently. Very recently, four labs independently identified the causative gene for $\mathrm{UV}^{\mathrm{S}} \mathrm{S}-\mathrm{A}$, either by exome sequencing of $U V^{S} S-A$ patients, microcell-mediated chromosome transfer, proteomic analysis of CSA interacting proteins, or 
by dissecting the UV-induced ubiquitin-proteome (Fei and Chen 2012; Nakazawa et al. 2012; Schwertman et al. 2012; Zhang et al. 2012).

The large difference in phenotypic expression between $\mathrm{UV}^{\mathrm{S}} \mathrm{S}$-causing and $\mathrm{CS}$-causing mutations, each equally affecting TC-NER of UV lesions at the cellular level, is difficult to reconcile with currently available knowledge. It has been noted, however, that CS cells are sensitive to oxidative DNA damaging agents ( $\mathrm{Ha}-$ nawalt and Spivak 2008), whereas cells from $\mathrm{UV}^{\mathrm{S}} \mathrm{S}$ patients are not (Spivak 2005). It was suggested that in CS cells, endogenously produced oxidative DNA damage (induced by by-products of normal cellular metabolism) interfere with proper transcription. This blocked or retarded transcription induces apoptosis or senescence, which affect normal tissue homeostasis, resulting in premature segmental aging (Hoeijmakers 2007). The absence of a TC-NER defect on oxidative DNA damage in $\mathrm{UV}^{\mathrm{S}} \mathrm{S}$ cells may thus explain the milder phenotype. It is thus crucial to dissect the mechanistic difference between TC-NER deficiency in $\mathrm{UV}^{\mathrm{S}} \mathrm{S}$ and CS to understand the molecular basis of DNA damage-associated syndromes and to understand the molecular basis of DNA damage-associated premature aging features as in CS.

To further understand the etiology of CS, different mouse models have been generated in which $C s b$ or $C s a$ are disrupted (van der Horst et al. 1997, 2002). These mice recapitulate some of the CS clinical features (Gorgels et al. 2007; Jaarsma et al. 2011), but the features are much less pronounced than in man. This milder phenotype has been attributed to the shorter lifespan of mice ( $\sim 2.5$ years), possibly too short to acquire sufficient damage for significant effects. However, when these mice are crossed into mouse-models that are compromised in additional DNA repair processes to create double mutant mice, such as $\mathrm{Csb}^{-/-} / \mathrm{Xpa}^{-/-}$(TCNER deficiency with full disruption of NER), the aging features were strikingly aggravated (van der Pluijm et al. 2007). Thus, these mouse models mimic the full range of CS when additional pathways are defective. Generation of Uvssa-deficient mice will thus be instrumental in dissecting the molecular mechanism explain-
Transcription-Dependent Genome Surveillance

ing the difference in phenotypic expression between $\mathrm{CS}$ and $\mathrm{UV}^{\mathrm{S}} \mathrm{S}$.

\section{TRANSCRIPTIONAL ARREST AND ITS COUPLING TO DNA DAMAGE RESPONSE MACHINERIES}

It is evident from the above that prolonged impediment of transcription challenges genome integrity and cellular vitality and may contribute to human disease. It is thus of foremost importance to the cell to restore gene expression by effectively eliminating any burden that hinders RNAPII progression and to remove any persistently arrested polymerases as they may block new rounds of transcription and interfere with DNA replication. Based on experimental observations, several models have been proposed for the way cells respond when the progression of an actively transcribed RNAPII is blocked by DNA lesions and for the fate of the polymerase in cases of faulty repair. These involve stalling of RNAPII and its dislocation from the damaged chromatin, either by reverse translocation (backtracking) leading to RNAPII arrest or by dissociation from the chromatin and subsequent degradation of the polymerase, as well as lesion bypass by RNAPII (Brueckner et al. 2007; Marietta and Brooks 2007; Fousteri and Mullenders 2008; Cheung and Cramer 2011; Walmacq et al. 2012; Wilson et al. 2012).

RNAPII has been shown to stall at CPDs for at least $20 \mathrm{~h}$ in vitro (Selby et al. 1997) and for more than 48 hours in vivo in Csb-deficient mouse cells after UV-C irradiation (Garinis et al. 2009). Stalling of RNAPII at sites of UVand bulky helix-distorting lesions triggers the immediate activation of TC-NER for their removal. TC-NER is directly coupled to transcription elongation as it requires an actively progressing RNAPII (Christians and Hanawalt 1992; Sweder and Hanawalt 1992). TC-NER mainly occurs in the open reading frame of transcribed regions but not in promoters or regions downstream of transcription termination sites.

Coupling of damage-arrested RNAPII to accelerated repair depends on specific factors that are exclusively required for TC-NER but not GG-NER. These factors include the CSA and 
W. Vermeulen and M. Fousteri

CSB proteins, UVSSA, XAB2, and HMGN1. Cells with either a mutation or down-regulation of these factors show a greater reduction in the rate of repair of lesions in the transcribed versus the nontranscribed strand and/or increased UV sensitivity and a prolonged inhibition of RNA synthesis leading to a strong signal for cellular apoptosis (Troelstra et al. 1992b; Henning et al. 1995; Nakatsu et al. 2000; Spivak et al. 2002; Birger et al. 2003; Kuraoka et al. 2008; Fei and Chen 2012; Nakazawa et al. 2012; Schwertman et al. 2012; Zhang et al. 2012). Thus, although dispensable for the core repair process of NER/ GG-NER, these factors are crucial for TC-NER, underscoring the special requirements of this pathway.

Taking into account that the footprint of a CPD-stalled RNAPII will cover an area of $10 \mathrm{nu}-$ cleotides ahead of a CPD and 25 nucleotides behind (Tornaletti et al. 1999) and that forward translocation of the stalled RNAPII is disfavored (Brueckner et al. 2007), displacement of RNAPII seems the most likely option to provide access to the damaged template. Based on the above, a potential role for TC-NER-specific factors in effecting RNAPII dislocation from the damaged chromatin and/or triggering the recruitment of repair proteins has been suggested. Important insights into this process have been provided by a number of in vitro and in vivo studies (Fousteri et al. 2006; Lainé and Egly 2006), but the exact function of the individual TC-NER specific factors and the signals that trigger their action are as yet unknown and need to be established to obtain a comprehensive view on the molecular mechanism of TC-NER.

Lesion bypass by RNAPII has been reported to occur for particular types of DNA damage such as thymine glycol, 8-oxoguanine, and $\mathrm{O}^{6}$ methylguanine and may lead to transcriptional mutagenesis (Doetsch 2002; Charlet-Berguerand et al. 2006; Dimitri et al. 2008; Damsma and Cramer 2009). Bypass of bulky helixdistorting DNA adducts and UV photolesions has also been reported to occur in certain circumstances. However, this is probably a rare event as the presence of a CPD in the active site of RNAPII has been shown to strongly dis- favor forward translocation of RNAPII (Brueckner et al. 2007). Under certain conditions and likely with low frequency, bypass of helix distorting lesions such as CPDs and cyclo-dA may occur in yeast (Walmacq et al. 2012) and in NER deficient human cells (Marietta and Brooks 2007). Yeast RNAPII was shown to bypass CPDs via an intrinsic ability to perform errorfree translesion synthesis, whereas bypass of bulky lesions in human XP-A cells resulted not only in transcription mutagenesis but also in nonmutant transcripts. Surprisingly, in the absence of CSB $/ \operatorname{Rad} 26$ (the yeast orthologue of CSB) the bypassed products were reduced. These observations, in conjunction with the observed prolonged arrest of RNAPII at CPDs in the absence of functional CSB in mouse cells (Garinis et al. 2009), suggest that translesion transcription is linked to functional CSB. Although more experiments are required to delineate the regulation and rate of occurrence of this pathway in vivo, it is unlikely that in TCNER proficient cells, lesion bypass will be favored over repair of the lesions because this is a much slower and ineffective process (Brueckner et al. 2007). Considering that CSB has been shown to favor translesion synthesis by RNAPII, it is intriguing to speculate that bypass of bulky DNA lesions is the process that cells exploit as an emergency strategy to clear the highly cytotoxic persistently blocked RNAPII molecules in situations in which CSB is functional but TC-NER is not operational as in XP-A cells. An increased rate of translesion transcription in XP-A cells might provide a molecular explanation for the increased transcriptional mutagenesis observed in UV-exposed XP-A patients as well as for the stronger phenotype of CS defects as opposed to XPA defects, although each seems to be equally deficient in TC-NER. It thus seems likely that the CS factors are not only required for efficient repair of lesions but also to prevent permanent stalling of RNAPII.

\section{FATE OF A DAMAGE ARRESTED RNAPII}

Repair of helix-distorting lesions that are trapped inside the active site of RNAPII requires the repair factors to be able to access the lesion 
and thus restructuring of the large molecular machinery. It has been proposed that ubiquitylation and subsequent degradation of the damage arrested RNAPII will provide the required accessibility for TC-NER (Bregman et al. 1996). However, more recent studies have challenged this model by providing firm evidence that degradation of RNAPII only occurs as "a last resort" to clear the path from permanently arrested transcription machineries when TC-NER is not functional (Woudstra et al. 2002; Anindya et al. 2007). Ubiquitylation of RNAPII occurs via a highly regulated multistep process that involves monoubiquitylation of RNAPII, starting with the Nedd4 (Rsp5-Ubc5 in yeast) E3 ubiquitin ligase, followed by the action of Elongin $\mathrm{A} / \mathrm{B} / \mathrm{C}$ and Cullin5-Rbx2 (Elc1-Cul3 and Def1 in yeast) that promote lysine-48 linked polyubiquitin chains (reviewed by Wilson et al. 2012).

In line with this, it has been shown that UVdamage arrested RNAPII is in a complex with TC-NER factors indicating that RNAPII stays at the damaged sites during the early steps of repair (Fousteri et al. 2006; Anindya et al. 2010; Schwertman et al. 2012). This finding is further supported by structure-based approaches (Brueckner et al. 2007; Damsma et al. 2007) using a CPD lesion within the active site of RNAPII or a cisplatin lesion in front of RNAPII. These approaches revealed an unchanged conformation of RNAPII supporting a nonallosteric recruitment of repair factors and removal of the lesion-containing DNA fragment in the presence of the arrested RNAPII. Taken together these data support a model in which arrested RNAPII is not removed from damaged sites but is rather reverse translocated to provide enough space for the repair factors to assemble.

Therefore, backtracking of RNAPII upon CPD incorporation in its active site, a process for which evidence has been obtained from both in vitro and in vivo experiments leading to arrest of RNAPII and transcript cleavage (Donahue et al. 1994; Sigurdsson et al. 2010; Cheung and Cramer 2011), might be the preferred mechanism in mammalian cells. Importantly, backtracking also provides a mechanism for transcriptional proofreading; any mismatch in the RNA:DNA hybrid in the transcription bubble (as is the case with CPDs) would weaken the hybrid inducing immediate backtracking. Backtracked elongation complexes need to be rescued by transcript cleavage, to remove the $3^{\prime}$ protruding RNA part that contained the misincorporated nucleotide. Transcript cleavage is promoted by the elongation transcription factor TFIIS that stimulates an intrinsic mRNA cleavage activity of RNAPII (Reines et al. 1992; Kettenberger et al. 2003). TFIIS was shown to be recruited to sites of damage-arrested RNAPII in a CS-dependent manner (Fousteri et al. 2006). Accordingly, down-regulation of TFIIS in human cells impaired recovery of RNA synthesis after UV damage, but surprisingly did not significantly affect UV sensitivity, suggesting that TFIIS does not play an essential role in the TCNER process itself (Jensen and Mullenders 2010; Mackinnon-Roy et al. 2011). Within a series of elegant experiments in yeast, using different TFIIS mutants that either allowed or blocked transcript cleavage, it was shown that the intrinsic cleavage activity of the transcription elongating complex may be sufficient for resumption of transcription and cell survival in the absence of stimulated transcript cleavage by TFIIS (Sigurdsson et al. 2010). It is currently unclear how RNAPII backtracking and/or the assembly of the TC-NER machinery on the damaged template strand takes place in chromatin in vivo and whether specific chromatin changes occur on damage-driven transcriptional arrest.

\section{TC-NER COMPLEX ASSEMBLY AND FUNCTION OF TC-NER FACTORS}

The complexity of the TC-NER reaction involving restructuring or backtracking of the stalled RNAPII complex, assembly of NER factors, excision of the lesions, gap-filling synthesis, repositioning of the polymerase, and finally resumption of transcription, obviously demands a tight orchestration of the implicated activities. This complexity also severely hampers the analysis of TC-NER, exemplified by the difficulty to reach consensus on how TC-NER complexes are assembled. Early live cell studies showed that CSB transiently interacts with elongating RNAPII 
and that on DNA damage induction by UV light this interaction is stabilized (van den Boom et al. 2004). This probing function of CSB for RNAPII elongation processivity suggests an early role of CSB in damage sensing. On the other hand, in vitro studies have suggested that XPG and TFIIH are also implicated in the initial stage promoting ATP-dependent remodeling of the arrested RNAPII to allow recruitment of XPF/ ERCC1 endonuclease and permit accessibility of the damaged strand for nicking (Sarker et al. 2005). In these studies, however, no requirement for CSB or any of the other TC-NER exclusive factors had been shown except RNAPII itself (Laine and Egly 2006). However, in in vivo studies, designed to isolate and dissect active TC-NER complexes, it was shown by using CSB-deficient cells that CSB is one of the initial sensors of damage-arrested RNAPII and is essential for the recruitment of the NER core factors TFIIH, XPG, XPA, RPA, and XPF/ERCC1 (Fousteri et al. 2006). Moreover, CSB is required to attract the CSA-containing E3 ubiquitin ligase complex (Groisman et al. 2003) in association with the COP9 signalosome. CSB is a DNA-dependent ATPase that harbors a conserved helicase motif belonging to the SWI2/ SNF2 family of chromatin remodelers. Similar to other members of this family, CSB has no detectable helicase activity (Selby and Sancar 1997a) but has chromatin remodeling activity (Citterio et al. 2000). Point mutations in the CSB ATPase domains differentially affect its in vivo functions sensitizing the cells to UV irradiation and reducing its ability to rescue damage-inhibited RNA synthesis (Citterio et al. 1998; Muftuoglu et al. 2002). It remains unclear, however, whether recruitment of TC-NER factors depends on binding of CSB to the arrested RNAPII complex and/or whether it requires the remodeling activities of CSB. A number of functions have been allocated to CSB, including a role of CSB in transcription elongation, nucleosome assembly and histone tail binding, chromatin maintenance and remodeling, and strand annealing and exchange (Selby and Sancar 1997b; Citterio et al. 2000; Muftuoglu et al. 2006). In addition to its role in coupling RNAPII arrest and TC-NER, CSB has been reported to localize in mammalian nucleoli as a component of RNAPI transcription machinery together with TFIIH and XPG, and TC-NER of RNAPI transcribed genes were reported to occur in yeast (Bradsher et al. 2002; Conconi et al. 2002). Furthermore, CSB was shown to localize in mitochondria ( $\mathrm{mt}$ ) and has been implicated in the repair of stress/aging-induced lesions in mtDNA and in apoptosis-mediated loss of subcutaneous fat in mice (Aamann et al. 2010; Kamenisch et al. 2010). More research is required to verify these postulated functions and to reach a comprehensive molecular model of the CSB function in TC-NER.

\section{REGULATION OF TC-NER}

Given the importance of the CSB protein in TC-NER, it is reasonable to assume that its expression or activity may also be subject to regulation. It has been recently shown that an ATPdependent autoregulatory mechanism exists that ensures binding of CSB to chromatin in response to DNA damage (Lake et al. 2010). Whereas the amino-terminal part of CSB negatively regulates its association with DNA by sequestering the DNA-binding domain of the carboxy-terminal region in the absence of any stimuli, induction of DNA damage alleviates this effect and promotes CSB binding at the expense of ATP hydrolysis. Interestingly, a number of mutations found in CSB patients (R670W, W851R, and V957G) compromise the UV-induced association of CSB with chromatin. Furthermore, CSB contains an ubiquitin-binding domain that is indispensable for its function in TC-NER and the restoration of damage-inhibited RNA synthesis (Anindya et al.2010). Deletion of this ubiquitin-binding domain $\left(\mathrm{CSB}^{\mathrm{del}}\right)$ does not affect the association of CSB to sites of arrested RNAPII complexes nor does it affect TCNER complex assembly. However, this $\mathrm{CSB}^{\mathrm{del}}$ assembled complex shows a reduced rate of excision of DNA lesions and gets permanently immobilized at sites of damaged chromatin in contrast to the dynamic association seen by wildtype CSB. These data suggest that binding of CSB to a ubiquitylated partner would either promote excision of transcription-blocking lesions 
or it would enable the release of CSB from sites of damage-arrested RNAPII at later stages in TCNER. In the latter scenario, only a limited number of lesions would be repaired in the absence of recycling of $\mathrm{CSB}^{\mathrm{del}}$. As the CSA-E3 ubiquitin ligase complex is also assembled downstream of CSB at TC-NER sites in vivo, it is tempting to speculate that the CSA complex ubiquitylates the as-yet unidentified binding partner of CSB.

CSA is the dedicated substrate receptor (termed DCAF) of a DDB1-CUL4-RBX1 (CRL4) E3-ubiquitin ligase that is implicated in the regulation of TC-NER probably by ubiquitylating one or more factors involved in this pathway. CSA has seven WD40 repeat motifs, a short structural motif with $\beta$-propeller architecture that appears to be involved in proteinprotein interactions. It attaches to DDB1 via a helix-loop-helix motif (Fischer et al. 2011). A number of patient mutations in CSA were identified either at evolutionarily conserved amino acids in the WD40 repeat motifs or resulting in truncated CSA proteins lacking at least one WD40 repeat, which differentially affect the association of CSA with DDB1 or other proteins. Notably, mutations that are expected to cause only limited structural change give rise to milder forms of CS, whereas the more severe forms of CS are associated with mutations and deletions that are expected to severely alter CSA structure (Fischer et al. 2011). Crystal structure studies of the CSA-CRL4 and DDB2-CRL4 complexes support a common regulatory mechanism of CRL4 ${ }^{\mathrm{DCAF}(\mathrm{WD} 40)}$ E3-ubiquitin ligases, which involves inhibition by the COP9 signalosome (CSN) in a nonenzymatic fashion. This CSN mediated inhibition is alleviated by substrate binding to the specific DCAF (in this case CSA). Interestingly, CSA was shown to be autoubiquitylated in vitro and, whereas this event was shown to be inhibited by the CSN complex, addition of CSB relieved CSN inhibition leading to ubiquitylation of both CSB and CSA (Fischer et al. 2011). Although CSA has not yet been shown to be modified in vivo, the above findings support a model in which CSA could be the ubiquitylated partner of CSB that upon autoubiquitylation and perhaps also ubiquitylation of CSB drives the release of both proteins
Transcription-Dependent Genome Surveillance

from TC-NER sites after completion of repair, as also suggested by Groisman and coworkers (Groisman et al. 2006). On the other hand, CSB has been recently reported to be polyubiquitylated and degraded by BRCA1 in a CSA-independent manner at early steps after UV irradiation rather than later after completion of TCNER (Wei et al. 2011). Additional studies are required to delineate these apparently contradictory observations.

The recently identified novel TC-NER factor UVSSA (UV-stimulated scaffold protein A), which is mutated in $U^{S} S-A$ patients, forms a complex with the ubiquitin-specific protease 7 (USP7) and plays a protective role in the early steps of TC-NER (Fei and Chen 2012; Schwertman et al. 2012; Zhang et al. 2012). In this process, the UVSSA protein seems to provide substrate specificity to the pleiotropic deubiquitylating USP7 enzyme. The UVSSA/USP7 complex, which was shown to travel along with RNAPII and to accumulate at damage-stalled transcription sites, stabilizes the RNAPII/CSB complex by counteracting polyubiquitylation of CSB and RNAPII.

Taking into consideration that UVSSA interacts with USP7, RNAPII, CSB, and CSA and that it was isolated as part of an UV-induced ubiquitylated complex, a picture emerges in which the coupling of damage-arrested transcription to TC-NER involves a much more extensive network of highly-regulated ubiquitylation and deubiquitylation events than previously anticipated.

The CSB-dependent CRL4 ${ }^{\mathrm{CSA}}$ complex assembly at sites of damage-arrested transcription is required for the recruitment of the XPA-binding protein XAB2 (Nakatsu et al. 2000). XAB2 is an essential protein involved in pre-mRNA splicing and is indispensable for TC-NER and restoration of damage-inhibited RNA synthesis (Kuraoka et al. 2008). Thus, the implication of XAB2 in TC-NER links mRNA splicing to the arrest of transcription elongation, highlighting the multiple levels of complexity that regulate the DDR processes. Because XAB2 was identified in a two-hybrid screen as the binding partner of XPA and it is a tetratricopeptide-containing protein, a motif known to be implicated in 
protein-protein interactions, it is tempting to speculate that XAB2 might function as a scaffold that brings together RNAPII, splicing factors, and repair complexes. Nevertheless, additional work is required to address the role of $\mathrm{XAB} 2$ in TC-NER.

\section{IMPACT OF CHROMATIN ON DAMAGE- INDUCED TRANSCRIPTIONAL ARREST AND TC-NER}

Similar to other chromatin-templated processes, repair of DNA damage is complicated by the fact that genomic DNA is highly folded and packaged into the condensed structure of chromatin. It has been postulated that the "open" chromatin state in regions of actively transcribed genes is potentially connected with the enhanced repair of DNA lesions in these regions. This model is perhaps only relevant in highly differentiated cell types, such as neurons and macrophages, in which a so-called "transcription domain-associated repair" process is operational, which preferentially removes lesions from chromatin domains with active transcription (Nouspikel et al. 2006). However, a number of observations suggest that chromatin alteration at sites of damage-arrested RNAPII is causatively linked with the repair of the lesions and restoration of gene expression (see Lans et al. 2012 for review). These involve the essential function of the Swi2/Snf2-like CSB protein, which has also been shown to have chromatin remodeling activity (Citterio et al. 2000), the CSB-dependent recruitment of chromatin regulators such as the histone acetyltransferase (HAT) p300 (Fousteri et al. 2006), and the enhancement of TC-NER on treatment of cells with histone deacetylase inhibitors (Smerdon et al. 1982). Equally important is the recruitment of the nucleosomal nonhistone binding protein HMGN1 in a CSB- and CSA-dependent manner (Fousteri et al. 2006), which is known to increase HAT activity and unwind chromatin (Trieschmann et al. 1998; Lim et al. 2005).

Notably, HMGN1 ${ }^{-/-}$MEFs display enhanced UV sensitivity and show delayed removal of CPDs from the transcribed strand of active genes (Birger et al. 2003). Therefore, it is con- ceivable that remodeling of chromatin structure by either histone posttranslational modifications (PTMs) or nucleosome sliding might be critical for TC-NER and restoration of transcription. Although a number of different chromatin PTM-modifying and ATP-dependent remodeling activities have been linked to NER (Lans et al. 2012), it is likely that some are specifically implicated in TC-NER, although the identity of these needs to be ascertained.

Based on the above we propose the following model (Fig. 2): RNAPII needs to reverse translocate ("backtrack") upon encountering a DNA lesion to provide access for the NER factors to the damaged template. Within the context of chromatin, backtracking of RNAPII might be obstructed as a result of nucleosome reassembly behind the progressing RNAPII. This would render the $3^{\prime}$ side of the damage (which is bound by RNAPII) inaccessible to the TC-NER factors. We speculate that a regulatory cascade of specific histone modifications in concert with chromatin remodeling factors, presumably upstream of RNAPII arrest, is triggered by the CSBand CSA-dependent recruitment of p300 and HMGN1. These modifications and resulting remodeling events are required to create accessibility and/or affect RNAPII backtracking.

In summary, this cascade of events allows sufficient backtracking of RNAPII to provide the required space for the assembly of the NER machinery and enables UVSSA/USP7 to stabilize CSB/RNAPII by its deubiquitylating activity to create more time for repair. This then allows transcription to resume before the cell proceeds to an alternative pathway for the removal of the persistently arrested RNAPII complexes.

\section{CONCLUDING REMARKS}

From the above summary of the related literature it is evident that the regulation of TC-NER in mammals and its active coupling to stalled RNA polymerases is a particularly complex process that requires the coordination of a plethora of factors and associated pathways. Key factors in this process are the CS proteins that play pivotal roles not only in the assembly of functional TC-NER complexes but likely also in 


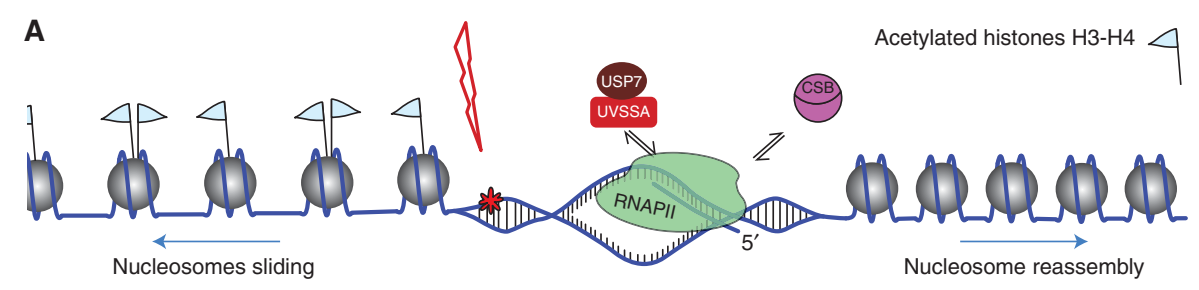

Transcription
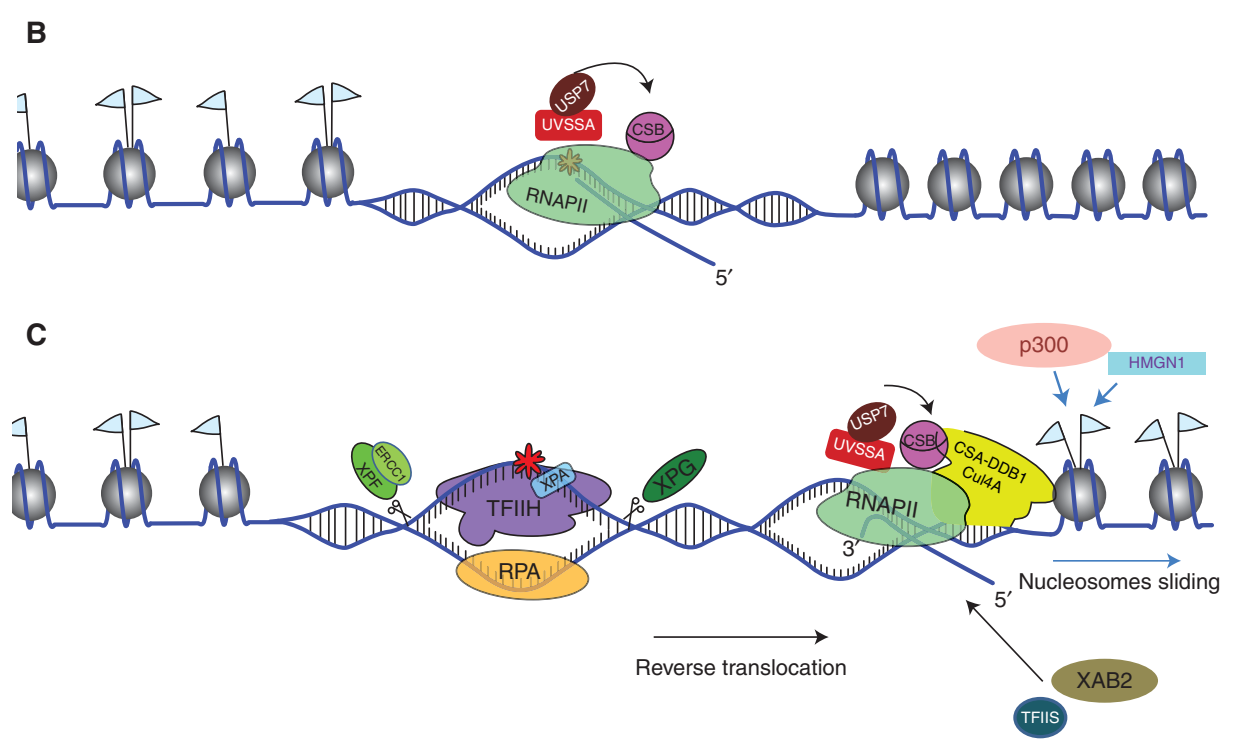

Figure 2. Model of mammalian TC-NER. (A) During transcription elongation RNAPII travels along with CSB as well as UVSSA/USP7 complex. (B) The progression of such transcribing polymerases may be impaired by DNA lesions that prevent forward translocation of the transcription machinery resulting in RNAPII stalling or arrest and stabilization of the CSB/RNAPII interaction. This results in the assembly of UVSSA/USP7 complex at the damaged site protecting CSB from untimely degradation events. (C) CSB triggers the recruitment of the CRL4 4 CSA complex and orchestrates the events that are required to couple the arrested RNAPII complex to chromatin remodeling events, mRNA splicing and NER. These remodeling events, mediated by p300 and HMGN1, are likely to occur upstream of the stalled RNAPII thus enabling RNAPII backtracking and assembly of the NER core machinery on both sides of the damage. Removal of the damage promotes cleavage of the protruding $3^{\prime} \mathrm{mRNA}$ (possibly stimulated by TFIIS) and resumption of transcription.

protecting the cells from permanently blocked transcription machineries. Despite the relatively large number of studies, important questions remain on the exact dynamic composition and regulation of the TC-NER mechanism that the cells exploit to clear lesion-stalled RNAPII complexes, and big gaps in our understanding remain to be filled. Moreover, we still lack insight into the phenotype-genotype correlations of CS and related disorders.
The recent identification of the UVSSA gene may help in dissecting the mechanistic difference between TC-NER-deficiency in $\mathrm{UV}^{\mathrm{S}} \mathrm{S}$ and the additional pleiotropic effects in CS and thereby assist in our understanding of the molecular basis of the associated syndromes. The salient differences in phenotypic expression between the two TC-NER-deficient syndromes CS and $U^{S} S$ have been attributed to the lack of a transcription-coupled repair defect for oxida- 
tive DNA lesions in $\mathrm{UV}^{\mathrm{S}} \mathrm{S}$ cells as opposed to CS cells (Spivak and Hanawalt 2006). However, the notion that CS factors and in particular CSB are implicated in the response to oxidative DNA damage (Stevnsner et al. 2008) has been debated over the years, with sometimes conflicting data and models, ranging from reduced incision activity on an 8-oxo-G DNA substrate (Dianov et al. 1999) to the absence of this (Osterod et al. 2002), or implicating CSB in global genome base excision repair (BER) function by affecting the expression of the BER glycosylase OGG1 (Tuo et al. 2002). Also, whether 8-oxo-G lesions affect RNAPII elongation has been disputed by conflicting results, ranging from weak transcriptional interference to complete absence of an effect (Tornaletti et al. 2004; Charlet-Berguerand et al. 2006; Spivak and Hanawalt 2006; Khobta et al. 2009). Very recently, however, with the aid of the development of a novel laser-directed method to locally inflict oxidative DNA damage in living cells, a clear transcription-coupled recruitment of CSB to these lesions was observed (Menoni et al. 2012). It is expected that with this method and the identification of the UVSSA gene, the enigma of the absence of a severe phenotype in $\mathrm{UV}^{\mathrm{S}} \mathrm{S}$ as opposed to CS may be enlightened.

\section{ACKNOWLEDGMENTS}

We thank Athina Fousteri for drawing the TCNER model and the Baptiste family for sharing their pictures with the public (Fig. 1). This work was funded by the Marie Curie FP7-PIEF-GA2009-253544 to M.F., ERC-2012-StG-309612 to M.F., "ARISTEIA- 2429" to M.F., and by grants from ZonMW (The Netherlands Organization for Health Research and Development) 917.46.364, 912.08.031 to W.V., and from "the Association for International Cancer Research" (10-594) to W.V.

\section{References}

* Reference is also in this collection.

Aamann MD, Sorensen MM, Hvitby C, Berquist BR, Muftuoglu M, Tian J, de Souza-Pinto NC, Scheibye-Knudsen M, Wilson DM III, Stevnsner T, et al. 2010. Cockayne syndrome group B protein promotes mitochondrial DNA stability by supporting the DNA repair association with the mitochondrial membrane. FASEB J 24: 23342346.

Anindya R, Aygü O, Svejstrup JQ. 2007. Damage-induced ubiquitylation of human RNA polymerase II by the ubiquitin ligase Nedd4, but not Cockayne syndrome proteins or BRCA1. Mol Cell 28: 386-397.

Anindya R, Mari PO, Kristensen U, Kool H, Giglia-Mari G, Mullenders LH, Fousteri M, Vermeulen W, Egly JM, Svejstrup JQ. 2010. A ubiquitin-binding domain in Cockayne syndrome B required for transcription-coupled nucleotide excision repair. Mol Cell 38: 637-648.

Birger Y, West KL, Postnikov YV, Lim JH, Furusawa T, Wagner JP, Laufer CS, Kraemer KH, Bustin M. 2003. Chromosomal protein HMGN1 enhances the rate of DNA repair in chromatin. EMBO J 22: 1665-1675.

Bohr VA, Smith CA, Okumoto DS, Hanawalt PC. 1985. DNA repair in an active gene: Removal of pyrimidine dimers from the DHFR gene of CHO cells is much more efficient than in the genome overall. Cell 40: 359-369.

Bradsher J, Auriol J, Proietti de Santis L, Iben S, Vonesch JL, Grummt I, Egly JM. 2002. CSB is a component of RNA pol I transcription. Mol Cell 10: 819-829.

Bregman DB, Halaban R, van Gool AJ, Henning KA, Friedberg EC, Warren SL. 1996. UV-induced ubiquitination of RNA polymerase II: A novel modification deficient in Cockayne syndrome cells. Proc Natl Acad Sci 93: 1158611590 .

Brueckner F, Hennecke U, Carell T, Cramer P. 2007. CPD damage recognition by transcribing RNA polymerase II. Science 315: 859-862.

Charlet-Berguerand N, Feuerhahn S, Kong SE, Ziserman H, Conaway JW, Conaway R, Egly JM. 2006. RNA polymerase II bypass of oxidative DNA damage is regulated by transcription elongation factors. EMBO J 25: 5481-5491.

Cheung AC, Cramer P. 2011. Structural basis of RNA polymerase II backtracking, arrest and reactivation. Nature 471: 249-253.

Christians FC, Hanawalt PC. 1992. Inhibition of transcription and strand-specific DNA repair by alpha-amanitin in Chinese hamster ovary cells. Mutat Res 274: 93-101.

Citterio E, Rademakers S, van der Horst GT, van Gool AJ, Hoeijmakers JH, Vermeulen W. 1998. Biochemical and biological characterization of wild-type and ATPase-deficient Cockayne syndrome B repair protein. J Biol Chem 273: $11844-11851$.

Citterio E, Van Den Boom V, Schnitzler G, Kanaar R, Bonte E, Kingston RE, Hoeijmakers JH, Vermeulen W. 2000. ATP-dependent chromatin remodeling by the Cockayne syndrome B DNA repair transcription-coupling factor. Mol Cell Biol 20: 7643-7653.

Cockayne EA. 1936. Dwarfism with retinal atrophy and deafness. Arch Dis Child 11: 1-8.

Cockayne EA. 1946. Dwarfism with retinal atrophy and deafness. Arch Dis Child 21: 52-54.

Conconi A, Bespalov VA, Smerdon MJ. 2002. Transcriptioncoupled repair in RNA polymerase Itranscribed genes of yeast. Proc Natl Acad Sci 99: 649-654. 
Damsma GE, Cramer P. 2009. Molecular basis of transcriptional mutagenesis at 8-oxoguanine. J Biol Chem 284: 31658-31663.

Damsma GE, Alt A, Brueckner F, Carell T, Cramer P. 2007. Mechanism of transcriptional stalling at cisplatin-damaged DNA. Nat Struct Mol Biol 14: 1127-1133.

Dianov G, Bischoff C, Sunesen M, Bohr VA. 1999. Repair of 8-oxoguanine in DNA is deficient in Cockayne syndrome group B cells. Nucleic Acids Res 27: 1365-1368.

Dimitri A, Burns JA, Broyde S, Scicchitano DA. 2008. Transcription elongation past O6-methylguanine by human RNA polymerase II and bacteriophage T7 RNA polymerase. Nucleic Acids Res 36: 6459-6471.

Doetsch PW. 2002. Translesion synthesis by RNA polymerases: Occurrence and biological implications for transcriptional mutagenesis. Mutat Res 510: 131-140.

Donahue BA, Yin S, Taylor JS, Reines D, Hanawalt PC. 1994 Transcript cleavage by RNA polymerase II arrested by a cyclobutane pyrimidine dimer in the DNA template. Proc Natl Acad Sci 91: 8502-8506.

Fei J, Chen J. 2012. KIAA1530 protein is recruited by Cockayne syndrome complementation group protein $\mathrm{A}$ (CSA) to participate in transcription-coupled repair (TCR). J Biol Chem 287: 35118-35126.

Fischer ES, Scrima A, Bohm K, Matsumoto S, Lingaraju GM, Faty M, Yasuda T, Cavadini S, Wakasugi M, Hanaoka F, et al. 2011. The molecular basis of CRL4DDB2/CSA ubiquitin ligase architecture, targeting, and activation. Cell 147: 1024-1039.

Fousteri M, Mullenders LH. 2008. Transcription-coupled nucleotide excision repair in mammalian cells: Molecular mechanisms and biological effects. Cell Res 18: 73-84.

Fousteri M, Vermeulen W, van Zeeland AA, Mullenders LH. 2006. Cockayne syndrome A and B proteins differentially regulate recruitment of chromatin remodeling and repair factors to stalled RNA polymerase II in vivo. Mol Cell 23: 471-482.

Garinis GA, Uittenboogaard LM, Stachelscheid H, Fousteri M, van Ijcken W, Breit TM, van Steeg H, Mullenders LH, van der Horst GT, Bruüning JC, et al. 2009. Persistent transcription-blocking DNA lesions trigger somatic growth attenuation associated with longevity. Nat Cell Biol 11: 604-615.

Gillet LC, Schärer OD. 2006. Molecular mechanisms of mammalian global genome nucleotide excision repair. Chem Rev 106: 253-276.

Gorgels TG, van der Pluijm I, Brandt RM, Garinis GA, van Steeg H, van den Aardweg G, Jansen GH, Ruijter JM, Bergen AA, van Norren D, et al. 2007. Retinal degeneration and ionizing radiation hypersensitivity in a mouse model for Cockayne syndrome. Mol Cell Biol 27: $1433-$ 1441.

Graham JM Jr, Anyane-Yeboa K, Raams A, Appeldoorn E, Kleijer WJ, Garritsen VH, Busch D, Edersheim TG, Jaspers NG. 2001. Cerebro-oculo-facio-skeletal syndrome with a nucleotide excision-repair defect and a mutated XPD gene, with prenatal diagnosis in a triplet pregnancy. Am J Hum Genet 69: 291-300.

Groisman R, Polanowska J, Kuraoka I, Sawada J, Saijo M, Drapkin R, Kisselev AF, Tanaka K, Nakatani Y. 2003. The ubiquitin ligase activity in the DDB2 and CSA complexes
Transcription-Dependent Genome Surveillance

is differentially regulated by the COP9 signalosome in response to DNA damage. Cell 113: 357-367.

Groisman R, Kuraoka I, Chevallier O, Gaye N, Magnaldo T, Tanaka K, Kisselev AF, Harel-Bellan A, Nakatani Y. 2006. CSA-dependent degradation of CSB by the ubiquitinproteasome pathway establishes a link between complementation factors of the Cockayne syndrome. Genes Dev 20: $1429-1434$.

Hamel BC, Raams A, Schuitema-Dijkstra AR, Simons P, van der Burgt I, Jaspers NG, Kleijer WJ. 1996. Xeroderma pigmentosum-Cockayne syndrome complex: A further case. J Med Genet 33: 607-610.

Hanawalt PC, Spivak G. 2008. Transcription-coupled DNA repair: Two decades of progress and surprises. Nat Rev Mol Cell Biol 9: 958-970.

Hendriks G, Jansen JG, Mullenders LH, de Wind N. 2010. Transcription-coupled repair and apoptosis provide specific protection against transcription-associated mutagenesis by ultraviolet light. Transcription 1: 95-98.

Henning KA, Li L, Iyer N, McDaniel LD, Reagan MS, Legerski R, Schultz RA, Stefanini M, Lehmann AR, Mayne $\mathrm{LV}$, et al. 1995. The Cockayne syndrome group A gene encodes a WD repeat protein that interacts with CSB protein and a subunit of RNA polymerase II TFIIH. Cell 82: 555-564.

Hoeijmakers JH. 2007. Genome maintenance mechanisms are critical for preventing cancer as well as other agingassociated diseases. Mech Ageing Dev 128: 460-462.

Horibata K, Iwamoto Y, Kuraoka I, Jaspers NG, Kurimasa A, Oshimura M, Ichihashi M, Tanaka K. 2004. Complete absence of Cockayne syndrome group B gene product gives rise to UV-sensitive syndrome but not Cockayne syndrome. Proc Natl Acad Sci 101: 15410-15415.

Itoh T, Ono T, Yamaizumi M. 1994. A new UV-sensitive syndrome not belonging to any complementation groups of xeroderma pigmentosum or Cockayne syndrome: Siblings showing biochemical characteristics of Cockayne syndrome without typical clinical manifestations. Mutat Res 314: 233-248.

Itoh T, Fujiwara Y, Ono T, Yamaizumi M. 1995. UVs syndrome, a new general category of photosensitive disorder with defective DNA repair, is distinct from xeroderma pigmentosum variant and rodent complementation group I. Am J Hum Genet 56: 1267-1276.

Jaarsma D, van der Pluijm I, de Waard MC, Haasdijk ED, Brandt R, Vermeij M, Rijksen Y, Maas A, van Steeg H, Hoeijmakers JH, et al. 2011. Age-related neuronal degeneration: Complementary roles of nucleotide excision repair and transcription-coupled repair in preventing neuropathology. PLoS Genet 7: e1002405.

Jaspers NG, Raams A, Silengo MC, Wijgers N, Niedernhofer LJ, Robinson AR, Giglia-Mari G, Hoogstraten D, Kleijer WJ, Hoeijmakers JH, et al. 2007. First reported patient with human ERCC1 deficiency has cerebro-oculo-facioskeletal syndrome with a mild defect in nucleotide excision repair and severe developmental failure. Am J Hum Genet 80: 457-466.

Jensen A, Mullenders LH. 2010. Transcription factor IIS impacts UV-inhibited transcription. DNA Repair (Amst) 9: $1142-1150$

Kamenisch Y, Fousteri M, Knoch J, von Thaler AK, Fehrenbacher B, Kato H, Becker T, Dolle ME, Kuiper R, Majora 
W. Vermeulen and M. Fousteri

M, et al. 2010. Proteins of nucleotide and base excision repair pathways interact in mitochondria to protect from loss of subcutaneous fat, a hallmark of aging. J Exp Med 207: $379-390$.

Kettenberger H, Armache KJ, Cramer P. 2003. Architecture of the RNA polymerase II-TFIIS complex and implications for mRNA cleavage. Cell 114: 347-357.

Khobta A, Kitsera N, Speckmann B, Epe B. 2009. 8-Oxoguanine DNA glycosylase (Ogg1) causes a transcriptional inactivation of damaged DNA in the absence of functional Cockayne syndrome B (Csb) protein. DNA Repair 8: 309-317.

Kleijer WJ, van der Sterre ML, Garritsen VH, Raams A, Jaspers NG. 2006. Prenatal diagnosis of the Cockayne syndrome: Survey of 15 years experience. Prenat Diagn 26: $980-984$.

Kuraoka I, Ito S, Wada T, Hayashida M, Lee L, Saijo M, Nakatsu Y, Matsumoto M, Matsunaga T, Handa H, et al. 2008. Isolation of XAB2 complex involved in premRNA splicing, transcription, and transcription-coupled repair. J Biol Chem 283: 940-950.

Lainé JP, Egly JM. 2006. Initiation of DNA repair mediated by a stalled RNA polymerase IIO. EMBO J 25: 387-397.

Lake RJ, Geyko A, Hemashettar G, Zhao Y, Fan HY. 2010. UV-induced association of the CSB remodeling protein with chromatin requires ATP-dependent relief of $\mathrm{N}$-terminal autorepression. Mol Cell 37: 235-246.

Lans H, Marteijn JA, Vermeulen W. 2012. ATP-dependent chromatin remodeling in the DNA-damage response. Epigenetics Chromatin 5: 4.

Laugel V, Dalloz C, Tobias ES, Tolmie JL, Martin-Coignard D, Drouin-Garraud V, Valayannopoulos V, Sarasin A, Dollfus H. 2008. Cerebro-oculo-facio-skeletal syndrome: Three additional cases with CSB mutations, new diagnostic criteria and an approach to investigation. J Med Genet 45: 564-571.

Laugel V, Dalloz C, Durand M, Sauvanaud F, Kristensen U, Vincent MC, Pasquier L, Odent S, Cormier-Daire V, Gener B, et al. 2010. Mutation update for the CSB/ ERCC6 and CSA/ERCC8 genes involved in Cockayne syndrome. Hum Mutat 31: 113-126.

Lehmann AR. 1982. Three complementation groups in Cockayne syndrome. Mutat Res 106: 347-356.

Lim JH, West KL, Rubinstein Y, Bergel M, Postnikov YV, Bustin M. 2005. Chromosomal protein HMGN1 enhances the acetylation of lysine 14 in histone H3. EMBO J 24: 3038-3048.

Limsirichaikul S, Niimi A, Fawcett H, Lehmann A, Yamashita S, Ogi T. 2009. A rapid non-radioactive technique for measurement of repair synthesis in primary human fibroblasts by incorporation of ethynyl deoxyuridine (EdU). Nucleic Acids Res 37: e31.

Ljungman M, Zhang F. 1996. Blockage of RNA polymerase as a possible trigger for U.V. light-induced apoptosis. Oncogene 13: 823-831.

Mackinnon-Roy C, Stubbert LJ, McKay BC. 2011. RNA interference against transcription elongation factor SII does not support its role in transcription-coupled nucleotide excision repair. Mutat Res 706: 53-58.
Marietta C, Brooks PJ. 2007. Transcriptional bypass of bulky DNA lesions causes new mutant RNA transcripts in human cells. EMBO Rep 8: 388-393.

Mayne LV, Lehmann AR. 1982. Failure of RNA synthesis to recover after UV irradiation: An early defect in cells from individuals with Cockayne's syndrome and xeroderma pigmentosum. Cancer Res 42: 1473-1478.

Meira LB, Graham JM Jr, Greenberg CR, Busch DB, Doughty AT, Ziffer DW, Coleman DM, Savre-Train I, Friedberg EC. 2000. Manitoba aboriginal kindred with original cerebro-oculo-facio-skeletal syndrome has a mutation in the Cockayne syndrome group B (CSB) gene. Am J Hum Genet 66: 1221-1228.

Mellon I. 2005. Transcription-coupled repair: A complex affair. Mutant Res 577: 155-161.

Mellon I, Spivak G, Hanawalt PC. 1987. Selective removal of transcription-blocking DNA damage from the transcribed strand of the mammalian DHFR gene. Cell 51: 241-249.

Menoni H, Hoeijmakers JH, Vermeulen W. 2012. Nucleotide excision repair-initiating proteins bind to oxidative DNA lesions in vivo. J Cell Biol 199: 1037-1046.

Moser J, Kool H, Giakzidis I, Caldecott K, Mullenders LH, Fousteri MI. 2007. Sealing of chromosomal DNA nicks during nucleotide excision repair requires XRCC1 and DNA ligase III $\alpha$ in a cell cycle-specific manner. Mol Cell 27: $311-323$.

Muftuoglu M, Selzer R, Tuo J, Brosh RM Jr, Bohr VA. 2002. Phenotypic consequences of mutations in the conserved motifs of the putative helicase domain of the human Cockayne syndrome group B gene. Gene 283: 27-40.

Muftuoglu M, Sharma S, Thorslund T, Stevnsner T, Soerensen MM, Brosh RM Jr, Bohr VA. 2006. Cockayne syndrome group B protein has novel strand annealing and exchange activities. Nucleic Acids Res 34: 295-304.

Nakatsu Y, Asahina H, Citterio E, Rademakers S, Vermeulen W, Kamiuchi S, Yeo JP, Khaw MC, Saijo M, Kodo N, et al. 2000. XAB2, a novel tetratricopeptide repeat protein involved in transcription-coupled DNA repair and transcription. J Biol Chem 275: 34931-34937.

Nakazawa Y, Yamashita S, Lehmann AR, Ogi T. 2010. A semi-automated non-radioactive system for measuring recovery of RNA synthesis and unscheduled DNA synthesis using ethynyluracil derivatives. DNA Repair 9: 506-516.

Nakazawa Y, Sasaki K, Mitsutake N, Matsuse M, Shimada M, Nardo T, Takahashi Y, Ohyama K, Ito K, Mishima H, et al 2012. Mutations in UVSSA cause UV-sensitive syndrome and impair RNA polymerase IIo processing in transcription-coupled nucleotide-excision repair. Nat Genet 44: 586-592.

Nance MA, Berry SA. 1992. Cockayne syndrome: Review of 140 cases. Am J Med Genet 42: 68-84.

Nardo T, Oneda R, Spivak G, Vaz B, Mortier L, Thomas P, Orioli D, Laugel V, Stary A, Hanawalt PC, et al. 2009. A UV-sensitive syndrome patient with a specific CSA mutation reveals separable roles for CSA in response to UV and oxidative DNA damage. Proc Natl Acad Sci 106: 6209-6214.

Neill CA, Dingwall MM. 1950. A syndrome resembling progeria: A review of two cases. Arch Dis Child 25: 213-223. 
Nouspikel T, Lalle P, Leadon SA, Cooper PK, Clarkson SG 1997. A common mutational pattern in Cockayne syndrome patients from xeroderma pigmentosum group G: Implications for a second XPG function. Proc Natl Acad Sci 94: 3116-3121.

Nouspikel TP, Hyka-Nouspikel N, Hanawalt PC. 2006. Transcription domain-associated repair in human cells. Mol Cell Biol 26: 8722-8730.

Ogi T, Limsirichaikul S, Overmeer RM, Volker M, Takenaka K, Cloney R, Nakazawa Y, Niimi A, Miki Y, Jaspers NG, et al. 2010. Three DNA polymerases, recruited by different mechanisms, carry out NER repair synthesis in human cells. Mol Cell 37: 714-727.

Osterod M, Larsen E, Le Page F, Hengstler JG, Van Der Horst GT, Boiteux S, Klungland A, Epe B. 2002. A global DNA repair mechanism involving the Cockayne syndrome $B$ (CSB) gene product can prevent the in vivo accumulation of endogenous oxidative DNA base damage. Oncogene 21: 8232-8239.

Pena SD, Shokeir MH. 1974. Autosomal recessive cerebrooculo-facio-skeletal (COFS) syndrome. Clin Genet 5: 285-293.

Preus M, Fraser FC. 1974. The cerebro-oculo-facio-skeletal syndrome. Clin Genet 5: 294-297.

Reines D, Ghanouni P, Li QQ, Mote J Jr. 1992. The RNA polymerase II elongation complex. Factor-dependent transcription elongation involves nascent RNA cleavage. J Biol Chem 267: 15516-15522.

Sarker AH, Tsutakawa SE, Kostek S, Ng C, Shin DS, Peris M, Campeau E, Tainer JA, Nogales E, Cooper PK. 2005. Recognition of RNA polymerase II and transcription bubbles by XPG, CSB, and TFIIH: Insights for transcription-coupled repair and Cockayne Syndrome. Mol Cell 20: $187-198$.

Schärer OD. 2011. Multistep damage recognition, pathway coordination and connections to transcription, damage signaling, chromatin structure, cancer and aging: Current perspectives on the nucleotide excision repair pathway. DNA Repair (Amst) 10: 667.

* Schärer OD. 2013. Nucleotide excision repair in eukaryotes. Cold Spring Harb Perspect Biol doi: 10.1101/cshperspect. a012609.

Schwertman P, Lagarou A, Dekkers DH, Raams A, van der Hoek AC, Laffeber C, Hoeijmakers JH, Demmers JA, Fousteri M, Vermeulen W, et al. 2012. UV-sensitive syndrome protein UVSSA recruits USP7 to regulate transcription-coupled repair. Nat Genet 44: 598-602.

Scrima A, Konickova R, Czyzewski BK, Kawasaki Y, Jeffrey PD, Groisman R, Nakatani Y, Iwai S, Pavletich NP, Thoma NH. 2008. Structural basis of UV DNA-damage recognition by the DDB1-DDB2 complex. Cell 135: 1213-1223.

Selby CP, Sancar A. 1997a. Human transcription-repair coupling factor CSB/ERCC6 is a DNA-stimulated ATPase but is not a helicase and does not disrupt the ternary transcription complex of stalled RNA polymerase II. $J$ Biol Chem 272: 1885-1890.

Selby CP, Sancar A. 1997b. Cockayne syndrome group B protein enhances elongation by RNA polymerase II. Proc Natl Acad Sci 94: 11205-11209.

Selby CP, Drapkin R, Reinberg D, Sancar A. 1997. RNA polymerase II stalled at a thymine dimer: Footprint and effect on excision repair. Nucleic Acids Res 25: 787-793.
Sigurdsson S, Dirac-Svejstrup AB, Svejstrup JQ. 2010. Evidence that transcript cleavage is essential for RNA polymerase II transcription and cell viability. Mol Cell 38: 202-210.

Smerdon MJ, Lan SY, Calza RE, Reeves R. 1982. Sodium butyrate stimulates DNA repair in UV-irradiated normal and xeroderma pigmentosum human fibroblasts. J Biol Chem 257: 13441-13447.

Spivak G. 2005. UV-sensitive syndrome. Mutat Res 577: $162-169$.

Spivak G, Hanawalt PC. 2006. Host cell reactivation of plasmids containing oxidative DNA lesions is defective in Cockayne syndrome but normal in UV-sensitive syndrome fibroblasts. DNA Repair (Amst) 5: 13-22.

Spivak G, Itoh T, Matsunaga T, Nikaido O, Hanawalt $P$, Yamaizumi M. 2002. Ultraviolet-sensitive syndrome cells are defective in transcription-coupled repair of cyclobutane pyrimidine dimers. DNA Repair (Amst) 1: 629-643.

Stevnsner T, Muftuoglu M, Aamann MD, Bohr VA. 2008. The role of Cockayne Syndrome group B (CSB) protein in base excision repair and aging. Mech Ageing Dev 129: 441-448.

Sugasawa K, Akagi J, Nishi R, Iwai S, Hanaoka F. 2009. Twostep recognition of DNA damage for mammalian nucleotide excision repair: Directional binding of the XPC complex and DNA strand scanning. Mol Cell 36: 642653.

Svejstrup JQ. 2002. Mechanisms of transcription-coupled DNA repair. Nat Rev Mol Cell Biol 3: 21-29.

Sweder KS, Hanawalt PC. 1992. Preferential repair of cyclobutane pyrimidine dimers in the transcribed strand of a gene in yeast chromosomes and plasmids is dependent on transcription. Proc Natl Acad Sci 89: 10696-10700.

Tanaka K, Kawai K, Kumahara Y, Ikenaga M, Okada Y. 1981. Genetic complementation groups in cockayne syndrome. Somatic Cell Genet 7: 445-455.

Tornaletti S, Reines D, Hanawalt PC. 1999. Structural characterization of RNA polymerase II complexes arrested by a cyclobutane pyrimidine dimer in the transcribed strand of template DNA. J Biol Chem 274: 24124-24130.

Tornaletti S, Maeda LS, Kolodner RD, Hanawalt PC. 2004. Effect of 8-oxoguanine on transcription elongation by T7 RNA polymerase and mammalian RNA polymerase II. DNA Repair (Amst) 3: 483-494.

Trieschmann L, Martin B, Bustin M. 1998. The chromatin unfolding domain of chromosomal protein HMG-14 targets the $\mathrm{N}$-terminal tail of histone $\mathrm{H} 3$ in nucleosomes. Proc Natl Acad Sci 95: 5468-5473.

Troelstra C, Landsvater RM, Wiegant J, van der Ploeg M, Viel G, Buys CH, Hoeijmakers JH. 1992a. Localization of the nucleotide excision repair gene ERCC6 to human chromosome 10q11-q21. Genomics 12: 745-749.

Troelstra C, van Gool A, de Wit J, Vermeulen W, Bootsma D, Hoeijmakers JH. 1992b. ERCC6, a member of a subfamily of putative helicases, is involved in Cockayne's syndrome and preferential repair of active genes. Cell 71: 939-953.

Tuo J, Chen C, Zeng X, Christiansen M, Bohr VA. 2002. Functional crosstalk between hOggl and the helicase domain of Cockayne syndrome group B protein. DNA Repair (Amst) 1: 913-927. 
W. Vermeulen and M. Fousteri

van den Boom V, Citterio E, Hoogstraten D, Zotter A, Egly JM, van Cappellen WA, Hoeijmakers JH, Houtsmuller AB, Vermeulen W. 2004. DNA damage stabilizes interaction of CSB with the transcription elongation machinery. J Cell Biol 166: 27-36.

van der Horst GT, van Steeg H, Berg RJ, van Gool AJ, de Wit J, Weeda G, Morreau H, Beems RB, van Kreijl CF, de Gruijl FR, et al. 1997. Defective transcription-coupled repair in Cockayne syndrome B mice is associated with skin cancer predisposition. Cell 89: 425-435.

van der Horst GT, Meira L, Gorgels TG, de Wit J, VelascoMiguel S, Richardson JA, Kamp Y, Vreeswijk MP, Smit B, Bootsma D, et al. 2002. UVB radiation-induced cancer predisposition in Cockayne syndrome group A (Csa) mutant mice. DNA Repair 1: 143-157.

van der Pluijm I, Garinis GA, Brandt RM, Gorgels TG, Wijnhoven SW, Diderich KE, de Wit J, Mitchell JR, van Oostrom C, Beems R, et al. 2007. Impaired genome maintenance suppresses the growth hormone-insulinlike growth factor 1 axis in mice with Cockayne syndrome. PLoS Biol 5: e2.

Walmacq C, Cheung AC, Kireeva ML, Lubkowska L, Ye C, Gotte D, Strathern JN, Carell T, Cramer P, Kashlev M. 2012. Mechanism of translesion transcription by RNA polymerase II and its role in cellular resistance to DNA damage. Mol Cell 46: 18-29.

Wei L, Lan L, Yasui A, Tanaka K, Saijo M, Matsuzawa A, Kashiwagi R, Maseki E, Hu Y, Parvin JD, et al. 2011. BRCA1 contributes to transcription-coupled repair of DNA damage through polyubiquitination and degradation of Cockayne syndrome B protein. Cancer Sci 102: 1840-1847.

Wilson MD, Harreman M, Svejstrup JQ. 2012. Ubiquitylation and degradation of elongating RNA polymerase II: The last resort. Biochim Biophys Acta 1829: 151-157.

Woudstra EC, Gilbert C, Fellows J, Jansen L, Brouwer J, Erdjument-Bromage H, Tempst P, Svejstrup JQ. 2002. A Rad26-Def1 complex coordinates repair and RNA pol II proteolysis in response to DNA damage. Nature 415: 929-933.

Yang W. 2008. Structure and mechanism for DNA lesion recognition. Cell Res 18: 184-197.

Zhang X, Horibata K, Saijo M, Ishigami C, Ukai A, Kanno S, Tahara H, Neilan EG, Honma M, Nohmi T, et al. 2012. Mutations in UVSSA cause UV-sensitive syndrome and destabilize ERCC6 in transcription-coupled DNA repair. Nat Genet 44: 593-597. 


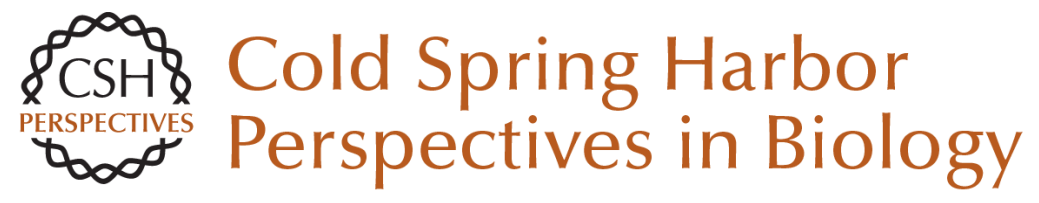

\section{Mammalian Transcription-Coupled Excision Repair}

Wim Vermeulen and Maria Fousteri

Cold Spring Harb Perspect Biol 2013; doi: 10.1101/cshperspect.a012625

Subject Collection DNA Repair, Mutagenesis, and Other Responses to DNA Damage

DNA Repair by Reversal of DNA Damage Chengqi $\mathrm{Yi}$ and Chuan He

Replicating Damaged DNA in Eukaryotes Nimrat Chatterjee and Wolfram Siede

DNA Damage Sensing by the ATM and ATR

Kinases Alexandre Maréchal and Lee Zou

Repair of Strand Breaks by Homologous Recombination

Maria Jasin and Rodney Rothstein

Advances in Understanding the Complex Mechanisms of DNA Interstrand Cross-Link

Repair

Cheryl Clauson, Orlando D. Schärer and Laura Niedernhofer

Ancient DNA Damage

Jesse Dabney, Matthias Meyer and Svante Pääbo

DNA Damage Response: Three Levels of DNA Repair Regulation

Bianca M. Sirbu and David Cortez

Alternative Excision Repair Pathways Akira Yasui
DNA Repair by Reversal of DNA Damage Chengqi Yi and Chuan He

Translesion DNA Synthesis and Mutagenesis in

Prokaryotes Robert P. Fuchs and Shingo Fujii

Nucleosome Dynamics as Modular Systems that Integrate DNA Damage and Repair Craig L. Peterson and Genevieve Almouzni

DNA Damage Responses in Prokaryotes:

Regulating Gene Expression, Modulating Growth

Patterns, and Manipulating Replication Forks Kenneth N. Kreuzer

Nucleotide Excision Repair in Eukaryotes Orlando D. Schärer

Biology of Extreme Radiation Resistance: The

Way of Deinococcus radiodurans Anita Krisko and Miroslav Radman

Mammalian Transcription-Coupled Excision

Repair

Wim Vermeulen and Maria Fousteri

DNA Repair at Telomeres: Keeping the Ends Intact Christopher J. Webb, Yun Wu and Virginia A. Zakian

For additional articles in this collection, see http://cshperspectives.cshlp.org/cgi/collection/

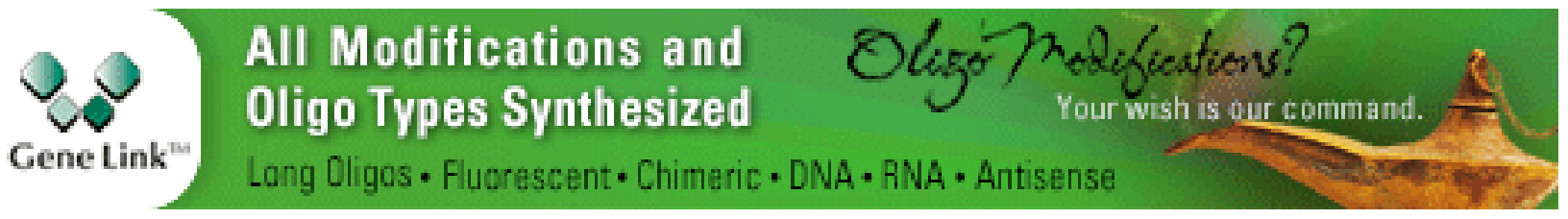

Copyright @ 2013 Cold Spring Harbor Laboratory Press; all rights reserved 